\title{
Recruiting to an infant formula-milk feeding trial: lessons from the baby milk trial
}

\author{
F Whittle ${ }^{*}$, K K Ong, S J Griffin, R Lakshman \\ From 3rd International Clinical Trials Methodology Conference \\ Glasgow, UK. 16-17 November 2015
}

\section{Background}

The Baby Milk Trial is a RCT of a multi-component intervention to prevent excessive milk intakes and weight gain in formula-fed infants. Healthy term infants receiving formula-milk are recruited up to 3 months old. There are both practical and social barriers to engaging this population, particularly the perceived stigma of formula-feeding from both the community and health professionals. We describe the recruitment methods employed in this study.

\section{Method}

A multi-level approach is used to identify formula-feeding parents through: Research Staff on a Postnatal Hospital ward; health professionals, including GPs, Midwives and Health Visitors; and via a mail-out using the NHS integrated database "Systm1". Eligible families are invited to attend recruitment visits at local research facilities or offered home visits if required.

\section{Results}

Over 650 infants have been recruited, identified through: GP Surgeries, 41\%; Systm1 mail-out, 28\%; Research Staff on postnatal wards, 23\%; Health Visitors, $1 \%$; Midwives $1 \%$; Other (including posters and word of mouth), $6 \%$. Having agreed to take part, more than $1 / 3$ of mothers asked for home visits rather than receive travel costs to attend local research facilities.

\section{Conclusions}

To identify formula-feeding families within 3 months of birth, GPs, research staff and a mail-out from a routine NHS database were effective strategies. Home visits reduce the burden on participants and facilitate recruitment and retention. Future research studies in this

University of Cambridge, Cambridge, UK

(c) 2015 Whittle et al. This is an Open Access article distributed under the terms of the Creative Commons Attribution License (http:// creativecommons.org/licenses/by/4.0), which permits unrestricted use, distribution, and reproduction in any medium, provided the original work is properly cited. The Creative Commons Public Domain Dedication waiver (http://creativecommons.org/publicdomain/ zero/1.0/) applies to the data made available in this article, unless otherwise stated. population should consider how to better engage with Health Visitors and Midwives who have the most frequent contacts with these families.

Published: 16 November 2015

doi:10.1186/1745-6215-16-S2-P121

Cite this article as: Whittle et al: Recruiting to an infant formula-milk feeding trial: lessons from the baby milk trial. Trials 2015 16(Suppl 2): P121. and take full advantage of:

- Convenient online submission

- Thorough peer review

- No space constraints or color figure charges

- Immediate publication on acceptance

- Inclusion in PubMed, CAS, Scopus and Google Scholar

- Research which is freely available for redistribution 